Gut, 1978, 19, 606-610

\title{
Low dose steroids and clinical relapse in Crohn's disease: a controlled trial
}

R. C. SMITH ${ }^{1}$, J. RHODES, R. V. HEATLEY, L. E. HUGHES, D. L. CROSBY, B. I. REES, H. JONES, K. T. EVANS, AND B. W. LAWRIE

From the Department of Gastroenterology and University Departments of Surgery and Diagnostic Radiology, University Hospital of Wales and Welsh National School of Medicine, Cardiff

SUMMARY The long-term effect of prednisone in Crohn's disease has been examined in a doubleblind controlled trial. Clinical relapse, recurrence, and extension of the disease were examined in 64 patients followed-up for up to three years. Fourteen patients were withdrawn because of severe symptoms (eight on prednisone and six controls); the withdrawal rate in both groups was $30 \%$ at three years. Nine other patients had radiological recurrence or extension of disease (five prednisone and four controls). Prednisone did not improve the relapse rate, nor did it affect recurrence or extension of disease.

One of the most daunting aspects of Crohn's disease is recurrence after surgery and extension of disease in spite of medical treatment. Short-term steroids lead to remission of symptoms in most patients with Crohn's disease; in one restrospective study (Jones and Lennard-Jones, 1966) 22 of 30 patients responded very quickly to therapy and in the current National Co-operative Crohn's Disease Study (NCCDS) steroids in a moderate dose (up to 0.75 mg prednisone per $\mathrm{kg}$ per day) caused a highly significant reduction in symptoms within two weeks and the improvement was maintained over four months (Singleton, 1976). Some patients appear to require steroids to control symptoms or 'disease activity' in the long-term and in two recent clinical trials (Willoughby et al., 1971; Rosenberg et al., 1975) where azathioprine was examined, withdrawal of steroids from these patients led to a recurrence of symptoms.

Although steroids reduced the severity of symptoms in acute disease, and in some patients control symptoms in the long term, their value in prevention of recurrence or extension of disease has not been examined. We have conducted a controlled trial to examine the effect of long-term treatment with prednisone on these aspects of Crohn's disease.

\section{Methods}

DESIGN OF TRIAL

Patients from South Glamorgan and adjacent areas

${ }^{1}$ Present address: University Department of Surgery, Leeds General Infirmary, Leeds.

Received for publication January 1978 were referred and examined in the clinic which was specially organised for the trial; all patients gave informed consent before entering the study. They were divided into three subgroups: (1) group I had bowel resected for Crohn's disease and had no obvious residual disease; (2) group II had also had recent surgery but there was residual disease; (3) group III were known to have active Crohn's disease but had not had surgery during the previous 12 months.

The patients who entered the trial were free from symptoms and there was no clinical indication for steroid treatment; all of them had contrast radiology to define the site and extent of disease. Those in groups I and II entered the trial within three months of surgery with a few exceptions who were all admitted within one year. The diagnosis was based on the pathology of resected specimens or on radiological findings in some patients entering group III.

\section{Patients excluded}

Patients were excluded from the trial if they were more than 60 years of age or had evidence of liver disease. Others were excluded if they had active peptic ulceration, severe hypertension, diabetes, previous pulmonary tuberculosis, or if they were pregnant at the onset of the trial.

\section{Trial design and treatment}

After admission to the trial patients were randomly allocated into groups on active or identical placebo tablets. Neither the patients nor medical staff were aware of the group to which the patients had been 
allocated. Five milligram tablets of prednisone were dispensed and patients were asked to take $7.5 \mathrm{mg}$ daily; children younger than 15 years had $7.5 \mathrm{mg}$ on alternate days. Additional symptomatic treatment with Lomotil, kaolin, vitamin capsules, and folic acid was continued in some of the patients. Eight others who were already taking sulphasalazine continued with this drug in a dose of between 1 and $5 \mathrm{~g}$ daily throughout the period of the trial.

Patients were seen in the trial clinic every six months when their symptoms were recorded and blood taken for haematological and biochemical measurements. Patients were examined and a sigmoidoscopy was usually carried out. Those patients who developed symptoms were seen at other times in addition to the six-monthly visit.

\section{Clinical relapse and withdrawal from trial}

A clinical relapse occurred when patients required additional prednisone to control recurrent or persistent abdominal symptoms; these symptoms usually consisted of malaise, weight loss, and colicky abdominal pain. At least two of the clinicians were involved in the decision to start prednisone, which was given in a dose of $20 \mathrm{mg}$ daily and an attempt was made to tail off the drug within six weeks. If the drug had to be continued for longer than six weeks, or if patients had a second relapse within 12 months, they were withdrawn from the trial.

\section{Radiological assessment}

Thirty-five patients who remained in the trial had further gastrointestinal radiology to define the extent of disease. These examinations were repeated after two years in the trial in 22 of the patients, but in nine of the patients after three years, and in four patients after one year in the trial. All of the radiology was carried out by the same two observers (KTE and BWL).

\section{Results}

Sixty-four patients were admitted to the trial but five of these were excluded within a few months of admission for reasons unrelated to their Crohn's disease. Two developed symptoms from peptic ulcer and three proved unreliable. The subsequent analysis relates to results from the remaining 59 patients.

Details of numbers in each subgroup and the randomisation are in Table 1 . Twenty-six were admitted to group I, 11 to group II, and 22 to group III. Details of the sex, age, distribution, and duration of disease in the prednisone and control groups are in Table 2; details of the patients in the two treatment groups were similar.

Of the 59 patients who completed the first six- month period, 54 completed 18 months, and 30 patients remained in the trial for three years. During this three-year period, 14 patients were withdrawn from the trial; eight were in the prednisone and six in the control group (Table 1). Only two of the 26 patients in group I were withdrawn compared with seven of 11 patients in group II and five of 22 patients in group III.

Table 1 Randomisation of patients and withdrawals from each group

\begin{tabular}{llcr}
\hline Group & Total & Prednisone & Placebo \\
\hline I & $26(2)$ & $14(1)$ & $12(1)$ \\
II & $11(7)$ & $8(5)$ & $3(2)$ \\
III & $22(5)$ & $11(2)$ & $11(3)$ \\
Total & $59(14)$ & $33(8)$ & $26(6)$ \\
\hline
\end{tabular}

The randomisation of patients on to treatment with either prednisone or placebo is given for the three subgroups; the numbers do not include five patients who were withdrawn during the first treatment period for reasons other than Crohn's disease. The number of patients withdrawn from each subgroup is given in parentheses.

Table 2 Clinical details of the two treatment groups

\begin{tabular}{lcc}
\hline & Prednisone & Control \\
\hline Sex & & \\
Male & 10 & 10 \\
Female & 23 & 16 \\
Age (yr) & 36 & 32 \\
$\quad$ Mean & 13 & 13 \\
Standard deviation & & \\
Duration of disease (yr) & 4 & $3 \cdot 5$ \\
$\quad$ Mean & 3 & $2 \cdot 5$ \\
Standard deviation & 18 & 11 \\
Distribution of disease & 12 & 11 \\
$\quad$ Small bowel only & 3 & 4 \\
Small and large bowel & 4 & 4 \\
Large bowel only & & \\
Patients also taking sulphasalazine & & \\
\hline
\end{tabular}

Clinical details of the 33 patients treated with prednisone and 26 controls.

The percentages of patients withdrawn from and remaining in the trial are represented as a 'life table estimate' in the Figure, which shows a withdrawal rate of $30 \%$ at three years in both treatment groups; there was no significant difference in the experience of the two groups during the three-year period as judged by the log rank test (Peto et al., 1976, 1977).

The site of the original disease in patients withdrawn from the trial was the small bowel in six, small bowel and colon in seven, and colon alone in one patient. Four of these patients subsequently had medical therapy which included an increased dose of steroids for several months. The remaining 10 patients had further surgery which included resection of the ileum in six patients combined with a right hemicolectomy in five of them. One patient had an abdominoperineal resection, one had a perineal 


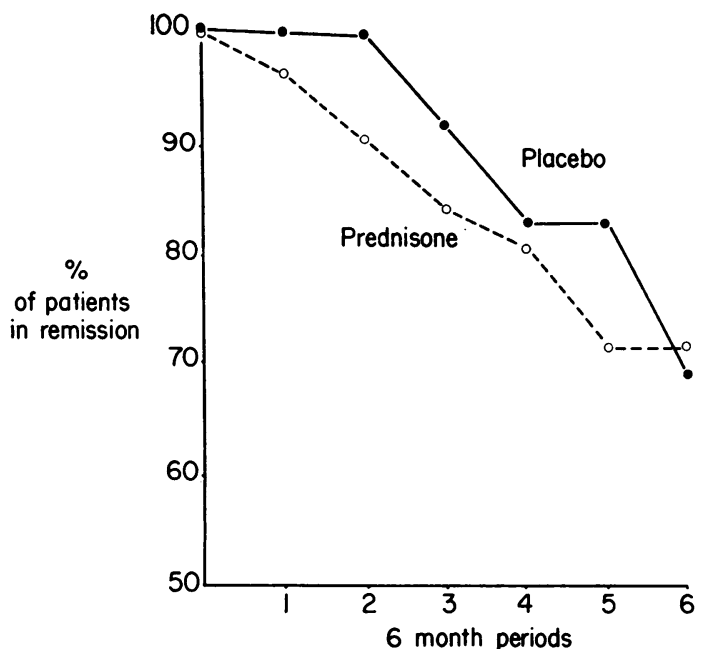

(Calculated as life table estimate)

Figure The number of patients who remained in the trial during the three-year period is plotted as for a life table estimate for both the placebo and prednisonetreated groups.

abscess drained, one had an extensive perineal fistula excised, and the remaining patient was found to have no apparent recurrent disease at laparotomy.

In addition to the 14 patients who were withdrawn from the trial, a further five patients had a single clinical relapse but were not withdrawn because steroids were tailed off within the six-week period; of these four were in the prednisone and one in the control group (Table 3).

The repeated radiological examinations showed clear evidence of recurrent disease in seven patients from group I although two of these had also had a single clinical relapse. Group I patients had no radiological evidence of disease on admission to the trial and recurrence was easy to identıfy. Another two patients in group III also had radiological evidence of extension of disease. One other patient had evidence of extension of disease on clinical grounds and developed inflamed rectal mucosa with perianal involvement after an ileal resection.

When consideration is given to patients who were withdrawn from the trial and additional patients in whom there was clear evidence of either recurrence or extension of disease radiologically, then during the three-year period the percentage of patients with a clinical relapse, recurrence or extension of disease was $45 \%$ in the prednisone and $42 \%$ in the control group.

\section{Discussion}

Our main findings relate to clinical relapse, recurrence, and extension of disease in a selected group of patients who were free from symptoms and did not require steroids on admission to the trial. The findings are based on patients who either had a clinical relapse or were withdrawn from the trial because of symptoms; these two events gave clear end-points with results which werealmost identical in the prednisone and control groups. Radiological recurrence or extension of disease without clinical symptoms added further data and again showed no difference between the two treatment groups. The relatively small dose of prednisone was chosen because it was sufficiently small to avoid complications in the majority of patients and yet from previous experience many patients with Crohn's disease have symptomatic benefit from $7.5 \mathrm{mg}$ daily. Any conclusions from our work relate to the effect of this dose of prednisone only. The first patient group enabled us to consider recurrence of disease where there appeared to be no residual involvement after surgery; in the 26 patients in this group only two were withdrawn but another seven patients had radiological evidence of recurrence and again there was no benefit in favour of the treated group. The radiological assessment was made without knowledge of the treatment and both observers in each case agreed that there was undoubtedly either recurrent or more extensive disease

Table 3 Patients with clinical relapse or radiological extension of disease

\begin{tabular}{|c|c|c|c|c|c|}
\hline Group & No. in group & Withdrawal & Single relapse & Radiological extension & Total patients involved \\
\hline \multicolumn{6}{|l|}{ I } \\
\hline Prednisone & 14 & 1 & 2 & 4 & 5 \\
\hline Control & 12 & 1 & - & 3 & 4 \\
\hline Prednisone & 8 & 5 & - & - & 5 \\
\hline Control & 3 & 2 & - & - & 2 \\
\hline \multicolumn{6}{|l|}{ III } \\
\hline Prednisone & 11 & 2 & 2 & 1 & 5 \\
\hline Control & 11 & 3 & 1 & 1 & 5 \\
\hline
\end{tabular}

The number of patients who were withdrawn from the trial or had a single medical relapse are shown together with those in whom there was radiological evidence of either recurrence or extension of disease. The figures are given for the prednisone and control patients in each group. 
present on the second examination; minor differences between the examination were not included in the results.

Figures for recurrence rates have varied from different centres; they are affected by the definition of recurrence, differences between patient groups and with the site of disease. Most figures are high and the longer the period for which a group is followed-up the higher the rate becomes. Crohn and Yarnis (1958) followed-up 542 cases for up to 25 years and only 51 of these remained well. Cooke (1955) reported a figure of $45 \%$ at two years, $68 \%$ at five years, and $78 \%$ at 10 years in a group of patients receiving both medical and surgical treatment. Lennard-Jones and Stalder (1967) used actuarial methods to calculate that one-third of all patients had symptomatic relapse within five years of a surgical resection of the terminal ileum and 50\% after 10 years. Another surgical series from the Mayo Clinic (Van Patter, 1954) showed a recurrence of disease in $80 \%$ of 270 patients, 15 years after the initial operation. Another large study involving 168 patients from Leeds (de Dombal et al., 1971) showed an overall recurrence rate of $34 \%$ in patients seen between 1939 and 1968 . The recurrence rate was less in patients with involvement mainly of the large rather than small bowel and was affected by age, with high recurrence rates in children and adolescents and low rates over the age of 60 years. Our results are compatible with some of the values in previous studies; the considerable variation from one centre to another emphasises the essential part of a control group in any study where the effect of therapeutic measures are examined in the long term.

A retrospective study by Cooke and Fielding (1970) suggested that long-term steroids were detrimental ; they examined the clinical course of 300 patients, 124 of whom had been given steroids, and found that the annual risk of surgery was $20 \%$ in those given steroids compared with only $10 \%$ without steroids. The authors pointed out that some of the severe complications and increased mortality were directly due to steroids. The current NCCD study in the United States (Summers and Singleton, 1977) again showed no benefit from steroids in the long term. The prophylactic effect of a low dose (less than $20 \mathrm{mg}$ daily) was examined after one and two years and compared with control patients; clinical or radiological deterioration had occurred in $32 \%$ in one year and in $69 \%$ after two years with no significant difference between the groups.

There are many difficulties involved in an assessment of long-term treatment in Crohn's disease. It is difficult to obtain a large homogeneous group of patients in a single centre and then follow them up for a sufficiently long time. Because of these problems, two recent studies (Multicentre Trial, 1977; Singleton, 1976; Summers and Singleton, 1977) have included many centres. It is particularly difficult to follow a group of patients for a long time and to maintain uniform standards for assessment and relapse. The study on sulphasalazine (Multicentre Trial, 1977) showed no trend in favour of the drug over the control group but the authors were concerned about difficulties in the trial due to small numbers, the involvement of nine hospitals, as well as the varied nature of the disease. The NCCDS group introduced a score of disease activity (Best et al., 1976) to overcome some of the difficulties in grading clinical severity. Some of these assessments are subjective and have been open to criticism on this basis. We tried to overcome some of the difficulties by creating three subgroups of patients, the first two of which were fairly homogeneous. The results are largely based on recurrence of disease in 14 patients who had to be withdrawn from the trial, and another nine patients who had evidence of radiological recurrence or disease extension.

We conclude that small doses of prednisone appear to have no beneficial effect on recurrence or clinical relapse in Crohn's disease but would recognise that there are patients who benefit symptomatically from this drug in both the short and long term.

We gratefully acknowledge help from Mrs B. Pelling and Miss J. Hopson for clerical assistance in running the trial. We are grateful to Roussel Laboratories who supplied the placebo tablets of prednisone and to the Department of Medical Illustration for the figure. Mr Robert Newcombe from the Department of Medical Statistics gave statistical help.

\section{References}

Best, W. R., Becktel, J. M., Singleton, J. W., and Kern, F. (1976). Development of a Crohn's disease activity indexNational Cooperative Crohn's disease study. Gastroenterology, 70, 439-444.

Cooke, W. T. (1955). Nutritional and metabolic factors in the aetiology and treatment of regional ileitis. Annals of Royal College of Surgeons, 17, 137-158.

Cooke, W. T., and Fielding, J. F. (1970). Corticosteroid or corticotrophin therapy in Crohn's disease (regional enteritis). Gut, 11, 921-927.

Crohn, B. B., and Yarnis, H. (1958). A review of our own experience with operative procedure for regional ileitis. In Regional Ileitis. Grune and Stratton: New York.

De Dombal, F. T., Burton, I., and Goligher, J. C. (1971). Recurrence of Crohn's disease after primary excisional surgery. Gut, 12, 519-527.

Jones, J. H., and Lennard-Jones, J. E. (1966). Corticosteroids and corticotrophin in the treatment of Crohn's disease. Gut, 7, 181-187.

Lennard-Jones. J. E., and Stalder, G. A. (1967). Prognosis after resection of chronic regional ileitis. Gut, 8, 332-336.

Multicentre Trial (1977). Sulphasalazine in asymptomatic 
Crohn's disease. Gut, 18, 69-72.

Peto, R., Pike, M. C., Armitage, P., Breslow, N. E., Cox, D. R., Howard, S. V., Mantel, N., McPherson, K., Peto, J., and Smith, P. G. (1976). Design and analysis of randomized clinical trials requiring prolonged observation of each patient. I. Introduction and design. British Journal of Cancer, 34, 585-612.

Peto, R., Pike, M. C., Armitage, P., Breslow, N. E., Cox, D. R., Howard, S. V., Mantel, N., McPherson, K., Peto, J., and Smith, P. G. (1977). Design and analysis of randomized clincial trials requiring prolonged observation of each patient. II. Analysis and examples. British Journal of Cancer, 35, 1-39.

Rosenberg, J. L., Levin, B., Wall, A. J., and Kirsner, J. B. (1975). A controlled trial of azathioprine in Crohn's disease. American Journal of Digestive Diseases, 20, 721726.

Singleton, J. W. (1976). National Cooperative Crohn's disease Study (NCCDS) Preliminary results of Part I. (Abstract.) Gastroenterology, 70, 938.

Summers, R. W., and Singleton, J. W. (1977). National Cooperative Crohn's Disease Study: a controlled prospective trial of three drugs vs placebo. Presented at the British Society of Gastroenterology, York, September 1977.

Van Patter, W. N., Bargen, J. A., Dockerty, M. B., Feldman, W. H., Mayo, C. W., and Waugh, J. M. (1954). Regional enteritis. Gastroenterology, 26, 347-447.

Willoughby, J. M. T., Kumar, P. J., Becket, J., and Dawson, A. M. (1971). Controlled trial of azathioprine in Crohn's disease. Lancet, 2, 944-947. 